\title{
El Parnaso en exilio: Adaptaciones cinematográficas de la literatura uruguaya durante el periodo silente
}

\author{
Parnassus in Exile: Film Adaptations of Uruguayan Literature \\ during the Silent Era
}

https://doi.org/10.22235/d34.2297

Georgina Torello

ORCID: 0000-0002-6491-769X

Universidad de la República, Uruguay.

\section{RESUMEN}

En el periodo del cine silente, la adaptación de obras literarias es una de las maneras que el nuevo medio encuentra para legitimarse y, por supuesto, para abastecer de tramas a producciones que se consumen con gran rapidez en los países donde la industria florece. Latinoamérica también participa de estos pasajes intermediáticos, aunque en la mayoría de los casos lo hace precariamente. El presente artículo se ocupa de tres adaptaciones cinematográficas de textos literarios uruguayos realizadas en el exterior: Tabaré, de Juan Zorrilla de San Martín (Lezama y Canals de Homs, México, 1917), Los muertos, de Florencio Sánchez (Defilippis Novoa, Argentina, 1919) y Brenda, de Eduardo Acevedo Díaz (Martínez y Gunche, Argentina, 1921). Desde una perspectiva transnacional, se indaga en las zonas de tensión, alianzas y resistencias que esos cruces entre cine y literatura generaron en Uruguay. Se destaca que en todos los casos la recepción implicó una apropiación de esas obras extranjeras como nacionales o regionales, hecho que lleva a una redefinición de lo extranjero, asociado por lo general a la industria norteamericana.

Palabras clave: cine silente; adaptaciones literarias; recepción; intermedialidad; Latinoamérica; Uruguay.

\begin{abstract}
In the silent cinema period, the adaptation of literary works was one of the ways the new medium found to legitimize itself and, of course, to supply plots for productions, that were consumed very quickly in the countries where the industry flourished. Latin America also participates in these inter-media passages, although in most cases it does it in a precarious way. This article addresses three film adaptations of Uruguayan literary texts made abroad: Tabaré, by Juan Zorrilla de San Martín (Lezama y Canals de Homs, Mexico, 1917), Los muertos, by Florencio Sánchez (Defilippis Novoa, Argentina, 1919) and Brenda, by Eduardo Acevedo Díaz (Martínez y Gunche, Argentina, 1921). From a transnational perspective, it explores the areas of tension, alliances and resistance that these crossings between cinema and literature created in Uruguay. In all cases, the reception implied an appropriation of these foreign works as national or regional, a fact that leads to a redefinition of the foreign, generally associated with the U.S. industry.
\end{abstract}

Keywords: silent cinema; literary adaptations; reception; inter-media; Latin America; Uruguay.

Cómo citar: Torello, G. (2021). El Parnaso en exilio: Adaptaciones cinematográficas de la literatura uruguaya durante el periodo silente. Dixit, 34, 78-94. https://doi.org/10.22235/d34.2297

Recepción: 30/09/2020 :: Revisión: 29/12/2020 :: Aceptación: 03/02/2021 


\section{Introducción}

Durante el periodo silente del cine, la producción latinoamericana de ficciones es episódica, y aún más episódica es su distribución en los mercados regionales o internacionales. A diferencia del periodo clásico en que se regulan, normalizan y consolidan los cines nacionales y, con ellos, también las relaciones entre los países (Lusnich, 2016, p. 104), en las primeras décadas del siglo XX, salvo algunas excepciones, solo es posible concebir para la región lo que Mette Hjort llama "formas débiles" de transnacionalidad (2010, p. 13). En una de esas formas participa la literatura uruguaya, elegida por productores mexicanos y argentinos para convertirla en nitrato gracias a las adaptaciones de Tabaré, de Juan Zorrilla de San Martín (Lezama y Canals de Homs, México, 1917), Los muertos, de Florencio Sánchez (Defilippis Novoa, Argentina, 1919) y Brenda, de Eduardo Acevedo Díaz (Martínez y Gunche, Argentina, 1921). ${ }^{1}$

En un mapa continental que hasta hace relativamente poco se pensaba como incomunicado, las tres películas logran, además, una discreta distribución. ${ }^{2}$ Se trata de formas débiles, pero significativas, de un "transnacionalismo por afınidad" que Hjort (2010) define a partir de Carley H. Dodd como "la tendencia a comunicar con aquellos similares a nosotros", entendiendo las similitudes en términos étnicos, lingüísticos, históricos (p. 17). Sobre esas afınidades se (re) construye un parnaso oriental que, pese a los numerosos impulsos nacionales, no se lograría crear en todo el cine silente uruguayo. Un parnaso cinematográfico elaborado y exhibido en el exterior, como también afuera concibieron, publicaron o estrenaron sus obras los autores tratados, por coyunturas políticas o económicas.

Como el $80 \%$ del corpus silente, las tres películas se encuentran, por el momento, perdidas. Resulta quimérica, por lo tanto, una perspectiva intermedial centrada en los pasajes del texto a la escena y, por ende, en las especificidades que los pasajes toman desde la mirada latinoamericana. Es necesario, sin embargo, recordar que estas producciones se incorporan a una práctica como la adaptación de textos literarios que había estado en la base de la narrativa silente desde sus comienzos, como estrategia de legitimación del nuevo medio en el mapa moderno de entretenimientos. De manera más o menos programática, a través de las adaptaciones, los productores habían agregado a las formas usuales de organización y difusión del canon literario, en tiempos de alfabetización precaria, una nueva y más accesible, popularizando las tramas y optimizando el tiempo y el dinero de sus espectadores.

A finales de siglo XIX y principios del siguiente, solo pocos minutos bastaban para ver, a un precio accesible, un drama shakespeariano, una tragedia griega o la Divina Comedia. Pero pasar de lo literario (ámbito de lo letrado y culto) a lo visual (contrapartida espectacular y popular) generó graves dudas entre los intelectuales. De hecho, parte clave de la recepción de las primeras adaptaciones de clásicos, a nivel global, tiene como voceros a cineastas e intelectuales que discuten pros y contras de la operación, incluidos los

\footnotetext{
* El presente artículo es una profundización y actualización de la ponencia "El Parnaso Oriental en exilio. Argentina y México adaptan la literatura uruguaya en el periodo silente", presentada en el III Simposio Iberoamericano de Estudios Comparados Prácticas y Relaciones Transnacionales en el Cine Latinoamericano Silente y Clásico, organizado por el Centro de Investigación y Nuevos Estudios sobre Cine (ClyNE, FFyL, UBA) y celebrado el 28 y 29 de julio de 2016.
}

$1::$ Utilizo el término "adaptación" y no "transposición" pues para el caso no se trata de "poner en otro sitio [...] pensando en otro registro o sistema" como define Wolf (2001) a esta última. En las primeras décadas del silente se busca que la literatura "quepa" en el nuevo formato, incluso materialmente, en pocos minutos, es decir, se "adapte" (pp. 15-16). El término es, además, utilizado regularmente en el periodo, por lo que la elección también evita anacronismos.

2:: Si bien existen investigaciones sobre la presencia, en el periodo silente, de las cinematografías hegemónicas (europea o norteamericana) en Latinoamérica, resultan raras las que se centran en las relaciones entre los países del continente. La escasez de estudios para las primeras décadas tiene que ver con la carencia de archivos especificos y sistematizados sobre las productoras y distribuidoras y sus emprendimientos intercontinentales. Para un estudio de las relaciones entre Uruguay y Argentina, y entre Argentina y México, véanse respectivamente Torello (2013) y Cuarterolo (2017). 
latinoamericanos (Borge, 2005; Bongers, Torrealba y Vergara, 2011). Para finales de la década del 10, sin embargo, los tiempos meteóricos de las primeras adaptaciones se extienden y, con ellos, la articulación de lo contado a través de medio y largometrajes. La literatura, de hecho, se instala, para quedarse, como insumo válido tanto de la omnívora industria cinematográfica del norte como de las formas artesanales que ella alcanza en la región.

El presente artículo indaga, a partir de fuentes secundarias, estos tres cruces entre cine y literatura, así como las múltiples zonas de tensión y debate que genera la vuelta del parnaso al Uruguay. De hecho, las campañas que involucran a Tabaré, Los muertos y Brenda instituyen en el país un espacio privilegiado para pensar la función de la literatura y del cine en la sociedad, la práctica misma de la adaptación y, específicamente, las implicaciones que esas adaptaciones tienen en términos patriótico-nacionales, regionales y globales.

El corpus en el "ambiente espiritual" de las primeras décadas del siglo

Para caracterizar "el ambiente espiritual del 900", Carlos Real de Azúa (1950) propone un cuadro tridimensional. Una puesta en escena -o tableau vivant- en que movimientos, ideologías y autores, manteniendo una distancia prudente, ocupan armónicamente el proscenio:

En una provisoria aproximación, podría ordenarse escenográficamente el medio intelectual novecentista hispanoamericano. Colocaríamos, como telón, al fondo, lo romántico, lo tradicional y lo burgués. El positivismo, en todas sus modalidades, dispondríase en un plano intermedio, muy visible sobre el anterior, pero sin dibujar y recortar sus contornos con una última nitidez. Y más adelante, una primera línea de influencias renovadoras, de corrientes, de nombres, sobresaliendo los de Nietzsche, Le Bon, Kropotkin, France, Tolstoy, Stirner, Schopenhauer, Ferri, Renán, Guyau, Fouillée... (p. 15).
Sus palabras sirven para ubicar sintéticamente a los tres literatos y las relaciones de concomitancia que ellos y sus obras tienen en el sistema cultural uruguayo y, por ende, su cabida en el del continente. Aunque también podríamos haberlos pensado, con Raymond Williams (1980), en términos de prácticas culturales emergentes, dominantes y residuales, el gesto del uruguayo tiene las ventajas con su recurso a la perspectiva de anticipar, trasversalmente, los pasajes del texto a la escena que interesan en el artículo.

Dos sitiales privilegiados ocupan, aunque "como telón, al fondo", en este ambiente cultural: la obra poética romántica de Juan Zorrilla de San Martín (Montevideo, 1855-1931) y la narrativa, igual de romántica, de Eduardo Acevedo Díaz (Montevideo, 1851 - Buenos Aires, 1921). Dentro de fronteras son, respectivamente, el poeta y el novelista de la patria, sus cantores más ilustres, los creadores de gestas.

Tabaré (1888) triunfa tanto a nivel nacional como internacionalmente, sobre todo si se considera la cantidad, y a menudo calidad, de las obras derivadas que genera: en pocos años se hacen numerosas traducciones a diferentes lenguas, hay reediciones en varios países de habla hispana y es, entre otras cosas, adoptado en los programas de enseñanza en la universidad parisina (Malosetti, 2018, pp. 18-19). La historia del indio de ojos azules será objeto, además, de trasposiciones musicales y visuales: quedándonos en los años 10 del siglo XX, además de interpretaciones gráficas de varios artistas e ilustradores, Tabaré inspira el poema lírico homónimo de 1910 -escrito por el uruguayo Alfonso Broca e inmediatamente representado en París- y, en 1913, una ópera también homónima del español Tomás Breton (Malosetti, 2018, pp. 20-21). En pocos años se convierte en estandarte -pese a los múltiples cortocircuitos que crea a la mirada de hoy- de la hermandad latinoamericana.

Brenda (1884-1885) también goza de una discreta victoria. Con el formato popularísimo del folletín aparece en La Nación de Buenos Aires, entre 1884-1885, y en La Razón de Montevideo a fines de 1885 . Al año siguiente 
se convierte en libro en Buenos Aires, donde se agota en poco tiempo (El editor, 1894, p. 1), y finalmente lo hace en 1894 en Montevideo, para los talleres de Barreiro y Ramos. Pero la atención trascendió el Río de la Plata: se la hizo objeto de una trasposición (plagiaria) a la zarzuela española y de una temprana traducción italiana en folletín, además de protagonizar una breve e infundada intriga sobre el eventual plagio de la novela perpetuado por Zola (Baccino Ponce de León, 1981, pp. 43-44). Producto de la transición entre romanticismo y naturalismo y, respectivamente, entre espiritualismo metafísico y positivismo, "subtema" de la novela (pp. 95-100), tuvo en su momento un notable éxito de público. El juicio crítico, en cambio, fue menos unánime, como emerge del primer estudio panorámico y documentado de la obra por Napoleón Baccino Ponce de León (1981). En él se identifica la tensión entre una crítica conservadora que la acoge con agrado -Mitre, Tobal, Vedia, Estrada y Magariños Cervantes- y una moderna que la azota igualmente complacida -Roxlo, Zum Felde, Lasplaces, Pérez Petit-; de ambos lados, pareciera, sin llegar a entender cabalmente su función en el corpus del escritor (p. 48, 55 y ss.).

En primer plano, y más cómodo que cualquier otro en la escena que Real de Azúa preparó, está el teatro de Florencio Sánchez (Montevideo, 1875 - Milán 1910), que interpela los resabios del romanticismo, lo tradicional y lo burgués, integra fragmentos de discursos positivistas y cientificistas y abraza las últimas tendencias del drama moderno digerido y elaborado con base en "las reglas de la escena local" (Dubatti, 2010). Si bien Los muertos (1905) no integra la terna de las obras mayores -M'hijo el dotor (1903), En familia (1905) y Barranca abajo (1905) - si formó parte de un secundario e "inmediato 'territorio selecto' junto con La Gringa y Un buen negocio" (Vidal, 2010, p. 15). Los estragos del alcoholismo dentro de un núcleo familiar, que la obra pone en escena, parecieron haber alcanzado una adherencia tal a la realidad que su estreno teatral, en el Buenos Aires de 1905 por los Hermanos
Podestá, dividió a la crítica argentina. Una parte de ella, como La Nación, lo censuró duramente por ese ambiente naturalista "adornado con los detalles más deprimentes" y por el mismo motivo otra parte, como La Tribuna, la consideró "una obra de verdad, ...un pedazo de vida arrojado a la escena” (Cúneo, 1941, p. 297). "Por los públicos, fue la más aplaudida", sentencia Cúneo netamente en su breve introducción a Los muertos (p. 297). El estreno montevideano, en abril de 1907 a cargo de la Compañía Lírica Española, parece haber sido más apacible. ${ }^{3}$ En todo caso, le seguirían durante las primeras décadas del siglo varios estrenos por elencos rioplatenses y extranjeros, entre ellos la Compañía Dramática Española de Andrés Cordero, la Compañía de Dramas Nacionales de Enrique Arellano y los cuadros filodramáticos anarquistas o entidades libertarias como CES Arroyo Seco, Emilio Zola y el Cuadro “Amor y Vida” (Braselli, 1998, pp. 81-83; Vidal, 2010, pp. 126-130). Antes de formar parte de la primera edición del Teatro Completo de Dardo Cúneo (Buenos Aires, 1941), tuvo por lo menos otras tres ediciones argentinas (1916, 1919 y 1933) y dos españolas: una valenciana en 1917 y una barcelonesa en 1919 (Rela, 1967, pp. 70-72).

Con sus discursos indigenistas, higienistas y políticos - declinados en prosa, verso y drama-, las tres obras se instalan en el cine latinoamericano para integrar, desde el nuevo medio, ese ambiente novecentista, intelectual y no, para participar, transformadas en nitrato, en las discusiones que, en sus formatos originales y dentro de las tradiciones literarias que representaban, habían generado entre la crítica. Este breve derrotero de la circulación y lugar que ocuparon las obras en el escenario nacional, latinoamericano e internacional quiere ser plataforma para pensar los humores y tensiones en que los tres proyectos fílmicos se insertaron.

3:: Aunque no hay un estudio específico sobre esta pieza, la crítica uruguaya, según las palabras de Daniel Vidal, parece haberla considerado entre las obras de "consensual valía" (2010, p. 15). 
Realismo, pedagogía, higienismo: Los muertos

Yo soy el abismo, la noche sombría Fantasma siniestro, que cruza, que pasa Yo soy el espanto, la melancolía El ábrego rudo que todo lo arrasa

Joaquín de Salterain, "La Copa» Lazo Blanco, 2, 7, mayo-junio de 1918

Los muertos, del director argentino Francisco Defilippis Novoa y protagonizado por María Esther Pomar de Podestà, Argentino Gómez y Félix Blanco, se estrena en Buenos Aires el 23 de junio de 1919, previa exhibición privada en abril del mismo año (Mafud, 2016, p. 289). El filme parece haber seguido ese naturalismo que marcó, gracias a la pluma sancheana, "el ingreso del teatro argentino y uruguayo al canon occidental", como señala Jorge Dubatti. La recepción de la película difiere, como su estreno teatral, a los lados del Río de la Plata. En Argentina, tras el preestreno, se reinstala el revuelo que el estreno teatral había causado, pero esta vez sus opositores son los exhibidores que, por sus contenidos inmorales, la boicotean (Mafud, 2016, p. 290). Desde la prensa especializada, sin embargo, se defiende como virtud que la versión conservara "la escabrosidad y la violencia del drama" (Imparcial Film [Argentina] I, 15, 15 de abril de 1919). Y, en la misma línea, la revista Excelsior dedica una página entera con las opiniones de intelectuales de la época. En ella, el director y crítico Joaquín de Vedia discurre sobre su calidad estética y, principalmente, sobre la pericia de la operación intramediática. Escribiendo directamente a su amigo Defilippis Novoa, ofrece una sintética proto-teoría de la transposición:

Ha hecho usted muy bien una cosa muy difícil: trasladar al cinema una pieza de teatro. Las reglas del uno son precisamente opuestas a las reglas del otro. Lo que recibe aquél de la síntesis, éste lo recibe del análisis. Se ha dicho siempre que la transformación de la novela en teatro resulta obra negativa, que priva a un género de sus recursos, sin ajustarse nunca a las buenas normas del otro género. Me parece que la adaptación de la obra teatral al cinema, tiene todavía mayores dificultades... El interés, la emoción, la fuerza dramática del original, nada pierden en su adaptación.... Los dos géneros se funden armoniosa y poderosamente en su versión cinematográfica (Excelsior [Argentina] 276, 25 de junio de 1919, p. 736). ${ }^{4}$

Contra la censura -o más exactamente la autocensura de los “dueños de cines"- embiste Santiago Profumo, poniendo en el tapete, además, la cuestión de clase:

¿Dónde está, pues, la inmoralidad? ¿Dónde el 'realismo' imposible de ser visto por la sociedad de los aristocráticos salones cinematográficos porteños? ¿Qué entienden por moralidad los señores empresarios que acusan a Sánchez de inmoral? ¿Ignoran que para cerrar las llagas hay que descubrirlas y que para cauterizarlas hay que hacer doler?

La sociedad argentina es suficientemente culta para tener tutores tan ignorantes. No podemos aceptar esa ridícula especie lanzada para desacreditar la única producción cinematográfica argentina que ha sido hecha con un alto fin patriótico de honestidad y arte. (Excelsior [Argentina] 276, 25 de junio de 1919, p. 736).

Con similares argumentos $-\mathrm{y}$ recurriendo también a la metáfora zolariana de la herida y el cuerpo socialopina el dramaturgo Julio F. Escobar, quien añade, en su arenga, el beneficio público: la obra es espejo, advertencia, "enseñanza". La defensa ataca, además, una moral hipócrita que, al tiempo que censura la obra sancheana,

4:: Agradezco a Andrea Cuarterolo que me aportó este artículo y los que cito en la nota siguiente. 


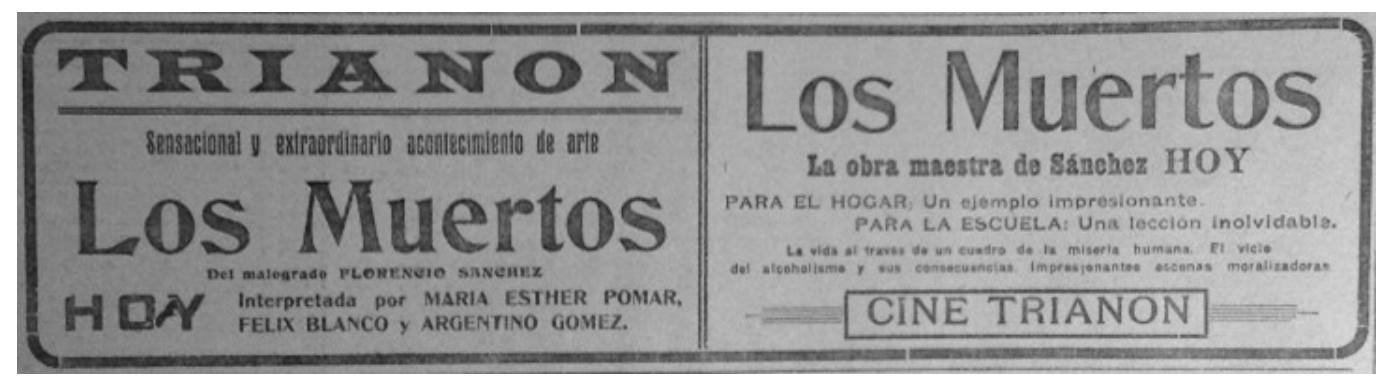

Figura 1: La ejemplaridad de Los muertos (El Plata, 26 de junio de 1920, p. 4)

elogia con criterios comerciales "películas policíacas, verdaderas escuelas de delito". ${ }^{5}$

La película se exhibe en Montevideo el 4 de noviembre de 1919, en el Cine Trianon, en función privada "ante un núcleo selecto de familias y periodistas", y se destaca al "joven periodista" Defilippis Novoa, como el "celebrado adaptador de Flor de Durazno", vista por Montevideo el año anterior. Para el público general, se estrena el 6 de ese mes, en el Teatro 18 de julio, como parte de los homenajes por el aniversario de la muerte del escritor. ${ }^{6}$

Desde El Plata se promociona el filme en base al éxito en la vecina república, mencionando sus casi "660 funciones bonaerenses" (El Plata [Uruguay], 5 de noviembre de 1919, p. 3) y sus aciertos estéticos que, dada la falta de toda imagen que la ilustre, son los únicos "datos visuales" disponibles: "perspectivas pintorescas de varias de sus escenas", "paisajes admirables de la gran metrópoli argentina, virajes preciosísimos y procedimientos de técnica que revelan en los autores de la adaptación una originalidad no superada hasta hoy en films nacionales" (El Plata, 6 de noviembre de 1919, p. 3). Pero se calla el alboroto causado por la polémica, quizá para prevenir eventuales discursos censorios -en esa dirección puede interpretarse que además de la publicidad genérica se defina un target específicamente femenino: "toda mujer amante de su hogar debe asistir" (El Plata, 5 de noviembre de 1919, p. 3).

La recepción de preestreno y estreno es positiva. Una como ejemplo del tono y la mirada:

La magistral obra de Florencio Sánchez resulta magnífica, en su adaptación al teatro del silencio. Los personajes se identifican con el público que sigue emocionado la trama dolorosa de la obra; que ve con dolor la desgracia de una familia por el vicio de su jefe. Los intérpretes han puesto de su parte al interpretar el film, todo su cariño y toda su admiración y respeto por la memoria del genial dramaturgo uruguayo. El actor Félix Blanco,

\section{TODA MUJER...}

* mante de su hogar debe asistir a la exhibición de la pelicula

\section{LOS MUERTOS}

del genial

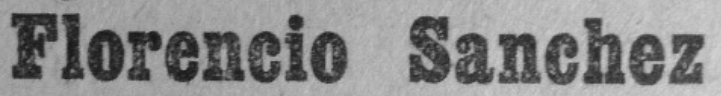

Se estrenará mañana jueves en el

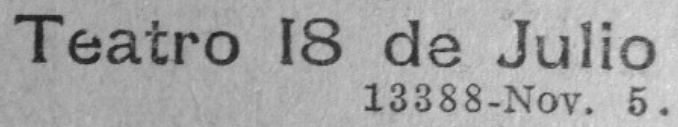

Figura 2: La construcción de una audiencia femenina en el aviso de Los muertos (El Plata, 5 de noviembre de 1919, p. 3)

de Montevideo hace una creación insuperable del doloroso papel de Lisandro Fuentes, secundando al actor Blanco eficazmente María Esther Pomar, el niño Gutiérrez, la señora Álvarez y Argentino Gómez. Ya hemos dicho que respecto a la fotografía y dirección artística la película Los muertos puede colocarse a la par de las mejores extranjeras. El público que asistió anoche a la primera exhibición, aplaudió calurosamente la obra (El Plata, 7 de noviembre de 1919, p. 5).

5:: Pese a ese comienzo tormentoso, la película será distribuida, junto con otras producciones argentinas, por diferentes compañias durante 1923-1924: Flor Film (La Película [Argentina], 345, 3 de mayo de 1923, p. 7), Cinematográfica Selección de Dasso \&t Cía, con sede en Buenos Aires, Rosario y Montevideo (La Película [Argentina], 418, 25 de setiembre de 1924, p. 44) y Terra Program (La Película, 425, 13 de noviembre de 1924, p. 20).

6:: El estreno se produce un día antes del que consigna en su libro fundamental Lucio Mafud (2016, p. 290). 
A pesar de los elogios se anuncia, sin otra explicación, que la película se exhibirá solo por pocos días en la capital. El 9 junio de 1920 se reestrena en el Teatro Solís, para mantenerse durante todo junio. Pero, a diferencia del año anterior, en que se habían exaltado las cualidades estéticas del filme, ahora se insiste en sus facultades moralizantes, alineándose con las tendencias higienistas y pedagógicas del momento.

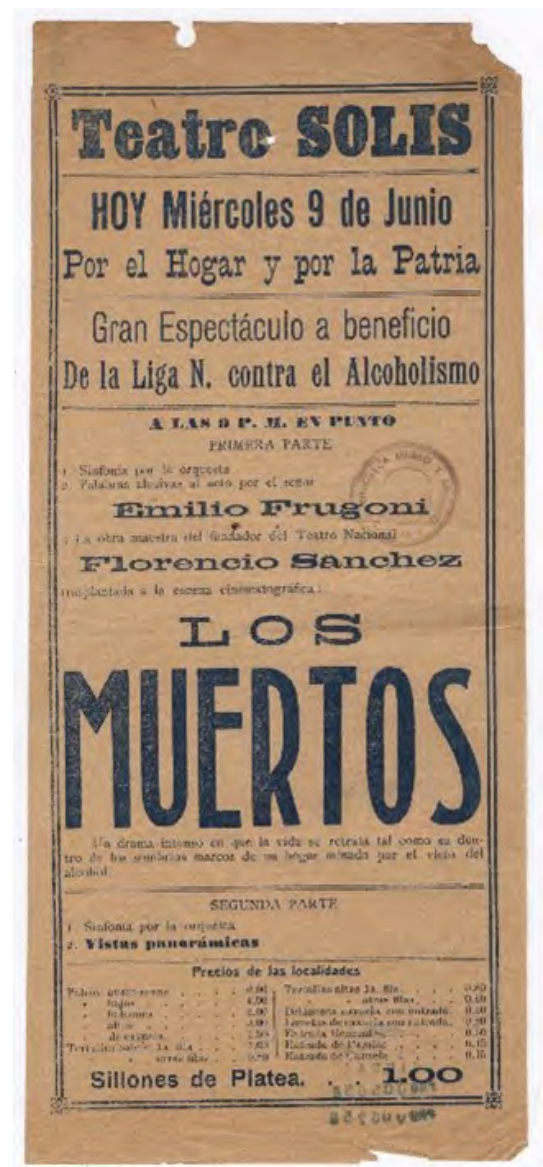

Figura 3: Programa de mano de Los Muertos, Teatro Solis, 9 de junio de 1920 (CIDDAE - Teatro Solís)
De hecho, el "mensaje" potencialmente instructivo de Los muertos parece tan inequívoco que la misma Liga Uruguaya contra el Alcoholismo lo adopta, invitando para la función de estreno al socialista Emilio Frugoni, quien ofrece una conferencia sobre el dramaturgo. El lobby antialcoholista (y transnacional) es capaz de unir, como fue señalado más de una vez, a las comunidades científicas y médicas, a las católicas, evangélicas y anarquistas (Bauck, 2016, p. 26; Bouret, 2009, p. 163).

En la reseña del espectáculo, desde El Siglo, se señala que Frugoni:

Habló de Los muertos, una obra honda, dolorosa, que sin haber sido creada para movilizar es una lección para quienes, por el vicio, pierden la voluntad, se hunden en el fango, resultan ex hombres. El doctor Frugoni fue aplaudido al final de sus palabras y recibió una ovación del público al terminar. Orador que la mayoría de las veces hace uso de la palabra en reuniones políticas, pudo (ilegible) apreciar sus excelencias el público femenino.

La cinta Los muertos obtuvo gran éxito trasplantando al cinematógrafo el poder de emoción que la pieza amarga de Sánchez causó en el teatro.

La Liga Anti Alcohólica puede estar satisfecha de su triunfo de anoche. (El Siglo [Uruguay], 10 de junio de 1920, p. 1).

La adopción de la obra sancheana entre los muchos instrumentos persuasivos de la Liga no extraña, aunque extraña menos aun que, desde El Siglo, se mencione algo socarronamente al "público femenino" o a la satisfacción de la Liga, dada la severidad de la asociación. Para "luchar sin tregua [y] triunfar sin alarde”, como rezaba el eslogan de su militante órgano de propaganda, la revista Lazo Blanco, la Liga había recurrido al poder de lo visual. Es, precisamente allí, donde se leen los versos de Salterain citados al principio de este apartado. Ellos condensan la 
“demonización del alcohol” que marcó buena parte de los discursos de la época (Bouret, 2009, p. 165) y que la Liga utilizará como métodos de combate. En la composición de Salterain, la copa parlante, metáfora fácil del alcohol que contiene, se adjudica - encarna- una serie de otras metáforas devastadoras: abismo, noche, fantasma siniestro, espanto, melancolía, viento. Pero en especial llega rápidamente al destinatario a través de la dimensión visual, del technopaegnion: la copa hecha con palabras impone inmediatamente al receptor ese objeto monstruoso que, si es débil, lo hará caer.

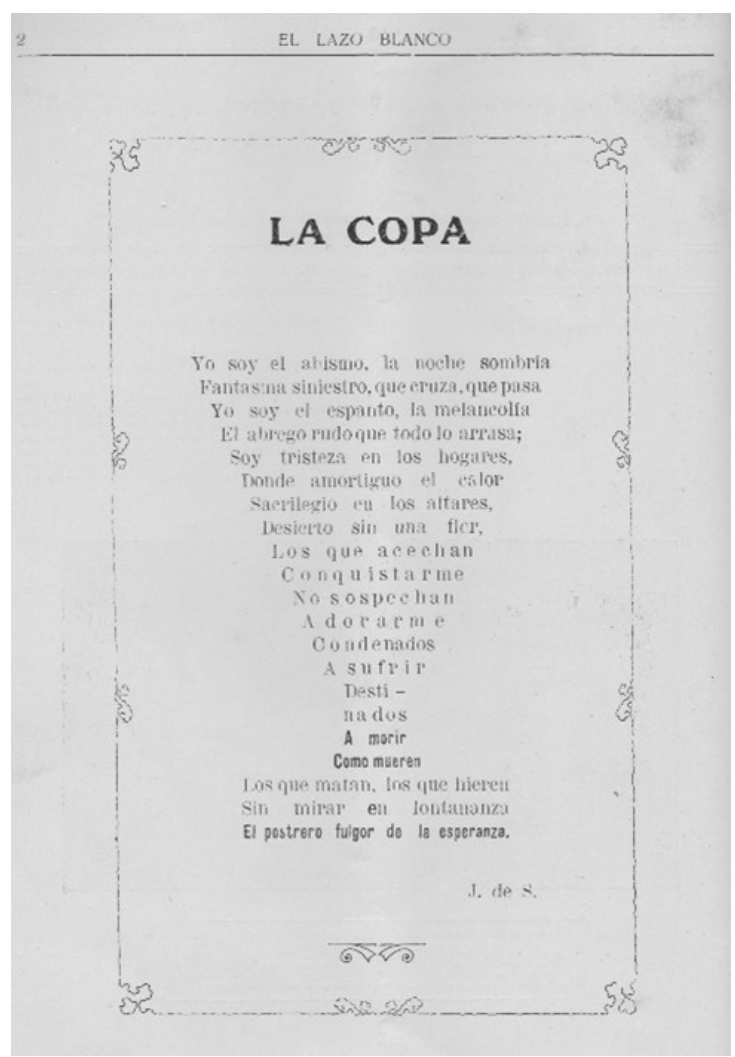

Figura 4: El technopaegnion, una estrategia de la campaña anti-alcoholista, Joaquín de Salterain, La Copa, Lazo Blanco, 2, 7, mayo-junio de 1918
La Liga también había confiado en el poder de las imágenes en movimiento casi desde sus inicios, en la década anterior, como en el caso del festival que la institución organiza entorno a la película El terrible veneno (Il grande veleno, Eugenio Testa, 1915), preocupándose de señalar que la escritura del guion era obra del "juez criminalista de la escuela lombrosiana Julio Caggiano” (La Razón [Uruguay], 2 de octubre de 1916) y legitimando así con marca higienista la entera empresa. Pero también se establecieron alianzas con el exhibidor Max Glücksmann que permitían amenizar fiestas "para familias obreras" donde la casa ofrecía "gratuitamente la exhibición de una vista de mucha trascendencia como ejemplo de los estragos del alcoholismo" (La Razón, 14 de junio de 1916, p. 4) o el "reparto de comestibles" donde se proyectaba ya no el genérico filme pedagógico, sino la extensa aunque no identificada Una copa de alcohol, en quince partes (La Razón, 29 de octubre de 1918, p. 3).

Como parte de la propaganda de Los muertos, la Liga recurre al saber médico y utiliza para sus comunicados la citada defensa de la argentina Excelsior, una vez más prescindiendo del contexto polémico:

Con espíritu esencialmente práctico emanado del ejercicio profesional; con la seguridad de ser la verdad la mejor escuela; con la convicción del positivo resultado de la enseñanza práctica que requiere la presentación del caso clínico: por haberme como médico legista, visto obligado a actuar en idénticos y parecidos casos; con ribetes de crítico sociólogo al atreverme a opinar; digo: ser Los muertos una obra de realismo, obra de actualidad, de enseñanza, de moral, obra en fin, de regeneración social transportada al cinematógrafo con singular maestría e interpretada por todos los artistas con altura y corrección. Luis Castiarena, Director de la Asistencia Pública, La Plata (Tribuna Popular [Uruguay], 7 de junio de 1920, p. 2).

La adaptación de Los muertos resulta, en la patria del artista, sobre todo un vehículo de orden moral, no así sus esfuerzos realistas y combativos. 


\section{Patria, latinoamericanismo y el otro: Tabaré}

Lumbre espirante que apagó la autora, Sombra desnuda muerta entre las zarzas, $\mathrm{Ni}$ las manchas siquiera De vuestra sangre en nuestra tierra guarda

Juan Zorrilla de San Martín, Tabaré

Tabaré, filmada por Luis Lezama a fines de 1917 y protagonizada por Carmen Bonifant, Emilia Cassani, Enrique Castilla y Juan Canals de Homs, se estrena en la Ciudad de México el 31 de enero de 1918. Retomaba ese poema de Zorrilla que, con adjetivación contemporánea, se podría decir sin dudas que fue un hit de la cultura del 900. Antes de concretarse en México, es en Argentina que se intenta llevar el poema a la pantalla: en 1915 la benéfica Asociación Escuelas y Patronatos, a través de la prensa, manifiesta esa intención, luego frustrada (La Razón, 20 de noviembre de 1915, p. 5).

Más tarde fue Ángel Barreiro quien, en medio de controversias sobre los derechos de autor (aunque aparentemente otorgados por Zorrilla mismo), encamina un proyecto porteño que también se frustra (La Razón 7 de julio de 1917, p. 1). Apenas una mención en un diario, en cambio, alude a un plan fílmico uruguayo, que hubiera propuesto una segunda versión, pero es evidentemente abortado en sus comienzos (La Razón, 2 de agosto de 1919, p. 5). Así, la primacía de la adaptación cinematográfica de Tabaré será mexicana, donde, dentro del empuje cultural de Venustiano Carranza, vale decir un clima de valorización de lo indígena y nacionalista, se pergeñaron películas ficcionales basadas en héroes nativos: es el caso de Tepeyac, que José Ramos y Carlos E. González dirigieron en 1917, y de Cuauhtémoc, dirigida por Manuel de la Bandera en 1918.

Es a raíz de un concurso de argumentos originales, ganado por Luis Lezama, que la película Tabaré se puede producir, gracias probablemente a la fama local de la obra literaria. No hay que olvidar que en 1892 se había publicado allí una edición "esmerada y corregida" del poema con prólogo de Juan de Dios Peza. Pese al foco sobre lo "propio" promovido por la cultura carrancista (sin bien, en este caso, "trasladado" de los mexicas a los charrúas), la película de Lezama sigue modelos formales europeos, no disimil de lo que había hecho Zorrilla con sus versos.

Aunque está perdida, el material gráfico sobre la película es abundante y nos acerca, aunque precariamente, a ella: existe el guion original; un folleto promocional publicado en concomitancia con el filme, que reproduce la historia y los versos del poeta, y numerosas fotos de escena. De ellas se desprende cómo estructura y estética derivan especialmente del cine italiano: cierta descripción estilizada del paisaje, monumentalismo y la organización esencialmente teatral de las escenas, frontales y estatuarias (Dávalos Orozco, 1998, p. 6; Sánchez García, 2013, p. 71). $\mathrm{Su}$ contenido -y la ideología que lo sostenía, si forma y contenido verdaderamente se pudieran separar-, no obstante, era indigenista y abocado a tender puentes entre México y Uruguay. Rafael Bermúdez Zataraín recordaría, muy a posteriori, que en el centro de la película palpitaba

El alma de los indios, de los indios sudamericanos, y de los nuestros también puesto que aun tratándose de un poema que no inspiró la raza azteca ni la tolteca... reconcentraba en sí el alma de los nativos de América” (Dávalos Orozco, 1998, p. 7).

Esto es algo que el guion de la cinta parece confirmar, pues acerca simbólicamente a los dos países en su comienzo: la abrían los retratos de Zorrilla de San Martín y Lezama, seguidos por un elocuente intertítulo: "La hermana patria me une a ti y quiero ser partícipe de tu compasión a Tabaré. Luis Lezama”"7

7:: "Tabaré. Novela histórica tomada del poema de Juan Zorrilla de San Martín y adaptada a la cinematografía por Luis Lezama". Archivo General de la Nación (México). Fondo de Propiedad Artística y Documental. Caja 312, expediente 9352, fojas 30. p. 2. Agradezco a Ángel Miquel por habérmelo proporcionado. Un diario montevideano menciona, de hecho, que el filme abría con el escudo de armas uruguayo y el retrato de Zorrilla (La Razón, 13 de junio de 1918, p. 5). 
En Montevideo, el estreno mexicano de Tabaré se clama con tinte oficial, mencionándose la asistencia de "nuestro" diplomático doctor Erasmo Callorda. Nada raro visto que lo que está en juego es el poeta de la patria. Para la ocasión, el diario La Razón transcribe el comunicado sobre el filme enviado al Ministerio de Relaciones Exteriores por la delegación uruguaya en México:

Un ingeniero adaptó la latitud del Uruguay con las del lugar en que debía imprimirse la película: otras personas estudiaron con conciencia las costumbres históricas de los charrúas y de los españoles.... Los charrúas están bien interpretados: son indios auténticos de Vera Cruz, vestidos como nuestros aborígenes. El medio ambiente idéntico al nuestro: vegetación no abundante, pero tampoco escasa; el terreno suavemente ondulado; el río Uruguay desembocando en el Plata bien nítido y hermosamente definido; la residencia de Don Gonzalo en el San Salvador bien española y semejante a nuestras casas de campo, de azotea colonial (La Razón, 13 de junio de 1918, p. 5)

El texto asegura con sus palabras, a la futura audiencia uruguaya, una verosimilitud tal que respeta "científicamente" historia y geografía. ${ }^{8}$ El comunicado se refiere, además, a la cita "literal" de la obra por el filme: cada situación dramática está precedida por dos o tres estrofas del poema "que influye mucho para el éxito de la vista”. Una alternancia que el crítico Ángel Miquel lee como la primera "exploración en México de las complejas relaciones entre la imagen poética y la visual", paragonando este experimento con producciones como Manhatta (Sheller y Strand, 1921), Tierra caucana (di Doménico, 1921) y La estrella de mar (Ray, 1928) que introducen, respectivamente, textos de Whitman, Nieto y Desnos (Miquel, 2017, p. 51). Las ventajas de las relaciones entre cine y literatura son además extracinematográficas: el poema, se informa en la nota, se habría agotado en las librerías mexicanas.
A la llegada de la película al país, programada para los primeros días de junio de 1920 en el Teatro Urquiza, La Razón dedica un extenso artículo. En él se informa detalladamente sobre la producción de la México Film, se recuerda el éxito del estreno mexicano y se vuelve sobre su lugar privilegiado en la cinematografía de aquel país: "esta es la primera película que se hace en México apegada a los cánones de la cinematografía moderna que exige interesante argumento, magnífica fotografía, correcta interpretación y si es de época apego estricto a la verdad histórica" (La Razón, 14 de mayo de 1920 , p. 7). En realidad, la nota no es otra cosa que una versión más extensa del comunicado de 1918 citado anteriormente, pero añade algo que el original no había mencionado: su "superioridad" (el artículo repite dos veces la palabra) respecto a las cintas "americanas y algunas extranjeras" y "a millares de las que importan" (La Razón, 14 de mayo de 1920, p. 7).

Se trata de todo un statement, pues lo agregado refiere a la tensión entre lo propio, lo regional y lo hegemónico con que la película había sido leída en México, donde se había abrazado la "meritoria labor de dar a conocer nuestros paisajes, nuestro ambiente poético en contraposición con los mamarrachos que allende el bravo presentan los gringos para humillar nuestro orgullo de raza y desprestigiar nuestra codiciada nacionalidad" (Rodríguez Beltrán citado en Dávalos Orozco, 1998, p. 13). Para el periodista mexicano, la epopeya del charrúa era metonimia de la lucha latinoamericanista contra un imperialismo norteamericano que, en la época, se pensaba tanto en términos territoriales como culturales (Torello, 2018, pp. 20-29).

La película, sin embargo, no llega sino varios meses más tarde. Tabaré se estrena en Montevideo, finalmente, el 3 de setiembre de 1920 en el Teatro Solís, con el acompañamiento musical "especialmente adaptado a la obra"

8:: Las referencias a la verosimilitud geográfica interesan particularmente visto que el motivo del paisaje en el cine nacional había sido y seguiría siendo candente para la representación de lo propio (Torello, 2018). 
por la orquesta del director Jorge Heyberger. Asisten a la función de gala el presidente de la República, Baltasar Brum, el cuerpo diplomático y, por supuesto, el mismo Zorrilla. Dado el éxito de público y crítica, se mantiene en cartel hasta el 9 del mismo mes, pues se anuncia que pasará "inmediatamente" a Argentina (El Plata, 2 de setiembre de 1920 , p. 4), aunque como sabemos eso no sucederá hasta 1925 (Cuarterolo, 2017). La distancia temporal entre mayo y setiembre, a primera vista solo anecdótica, determina cambios significativos en su presentación. Para setiembre desaparece toda referencia a su confección mexicana en la prensa y los programas de mano. En este segundo tiempo, la promoción se concentra en los valores literarios de la fuente ("la obra poética más gloriosa de nuestra literatura”),

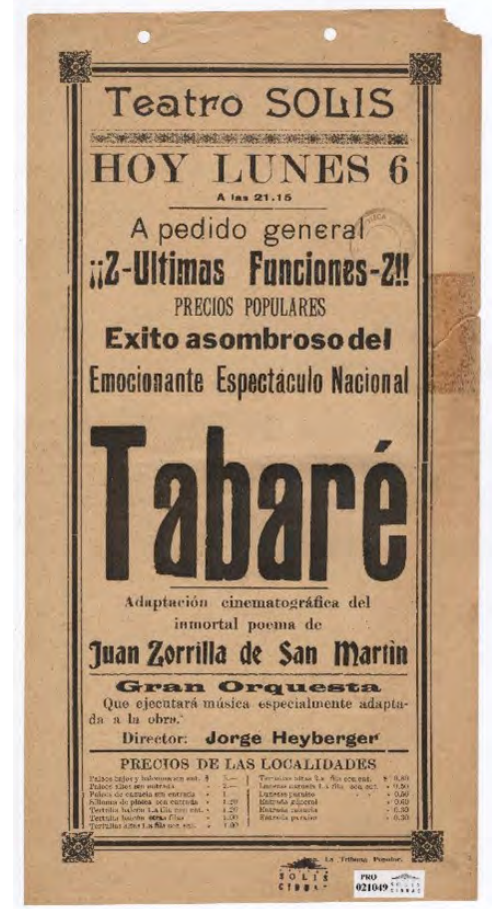

Figura 5: Programa de mano de Tabaré, Teatro Solís, 6 de setiembre de 1920 (CIDDAE - Teatro Solís) los técnico-estéticos de la traslación del poema a la cinta "hecha con los más modernos y artísticos recursos de la cinematografía" y el potencial pedagógico y nacional de esta "obra educadora de purísima moral y de excelso patriotismo" (El Pais [Uruguay], 2 de setiembre de 1920, p. 4).

La prensa menciona:

Es muy digno de hacerse notar que esta vez el público ha sabido despreocuparse de las sugestiones del renombre de los astros y estrellas del arte mudo, para concentrar toda su atención en 'la obra' en sí, interesándose en el romance, en el poema mismo, lo cual ya es muy digno de elogio" (El Plata, 6 de setiembre de 1920, p. 4).

El poema de Zorrilla logra que, por "esta vez", el público no solo renuncie a los placeres del star system hollywoodiano, sino que incluso sucumba ante lo visto:

El teatro hallábase totalmente ocupado, no sólo en palcos y plateas, sino también en cazuela y paraíso, que desbordaban materialmente de público que repetía con cariño los versos de Tabaré, a medida que estos hacíanse imagen en la pantalla. Uno de los pasajes más aplaudidos por espontánea inspiración del público, lo cual habla elocuentemente de nuestra cultura y de la inteligencia de nuestro pueblo, ya que esta es presumible en nuestra alta sociedad, fue el bautizo de Tabaré, a la orilla del río. ¿Se comprendió en efecto, que ese es el momento más grande, más trascendental de Tabaré? (El Plata, 4 de setiembre de 1920, p. 5).

Si el enfoque anterior había insistido en la unidad latinoamericana, este resaltaba la del pueblo uruguayo. Sin distinción de clase - del palco al paraíso- todo él recitaba los versos y, todo él, parecía comulgar con el mensaje cristiano encapsulado en la epopeya que se animaba ante sus ojos. 


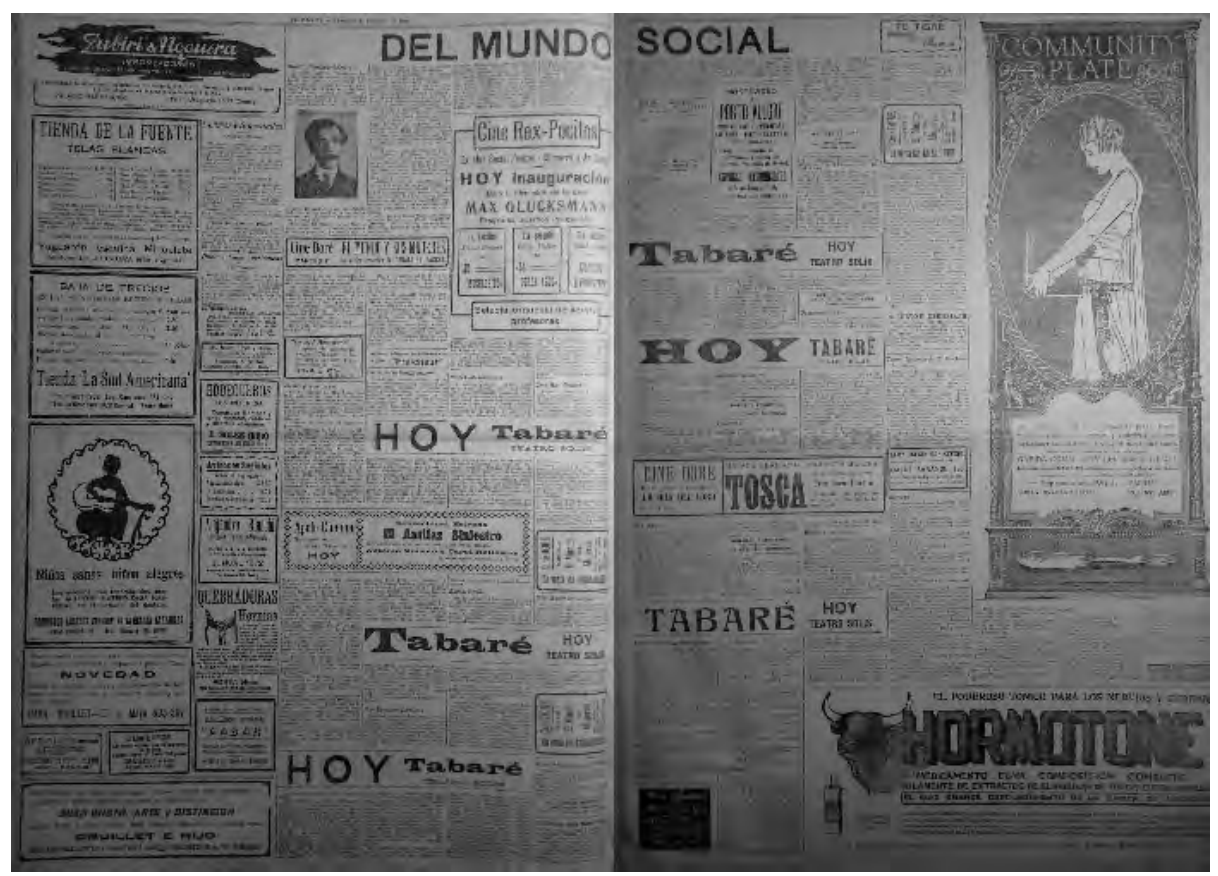

Figura 6: La página social y ocupación del espacio visual por Tabaré (El Plata, 3 de setiembre de 1920, p. 4-5)

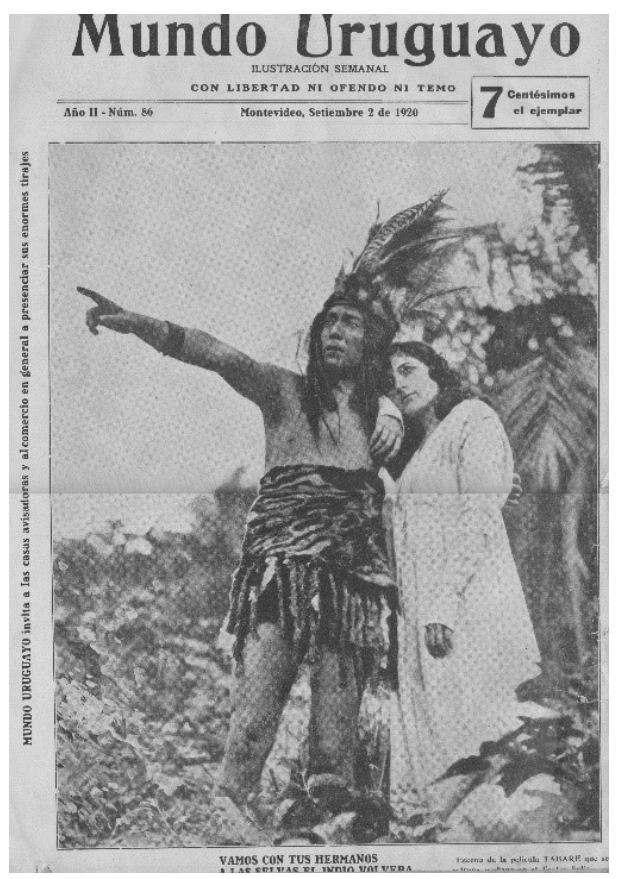

Figura 7: Tabaré en la tapa de Mundo Uruguayo (II, 86, 2 de setiembre de 1920)
Como las divas y los divos hollywoodianos, la pareja protagonista de Tabaré ocupa la tapa de la publicación generalista más importante del momento, Mundo Uruguayo, aunque en su interior no se haga referencia a la película. Y en la prensa cotidiana, la campaña de promoción va del simple recuadro con la información de funciones y precios a estrategias más ingeniosas y marketineras, como ocupar el espacio visual de las dos páginas sociales del diario, con repetidos anuncios, el día del estreno (El Plata, 3 de setiembre de 1920, p. 4-5) o, al día siguiente, en la misma página social, optar por un mensaje diversificado, dirigido en tono jocoso a cada miembro de la sociedad por separado: a la audiencia infantil, al joven, al señor, a la señorita, a los uruguayos, españoles, americanos (El Plata, 4 de setiembre de 1920, p. 4-5). Es una estrategia elocuente si consideramos que, durante las primeras tres décadas del siglo, dicha página reúne a menudo las noticias sobre cine, incluso cuando este conquista un espacio definido en la cartelera.

De la breve pero intensa campaña publicitaria se borra toda referencia a la nacionalidad del filme. Las razones se encuentran, como señalan Andrea Cuarterolo (2017) sobre la distribución argentina del filme y Ángel Miquel (2017) sobre la mexicana, en la apropiación (más o menos indebida) de la cinta por una compañía norteamericana. $Y$ si bien no es posible rastrear ese cambio de nacionalidad en el material de prensa relevado, rastros de esa deriva aparecen en un folleto, impreso bellamente por Barreiro y Ramos para los concesionarios Vázquez y Corralejo (hijo). 

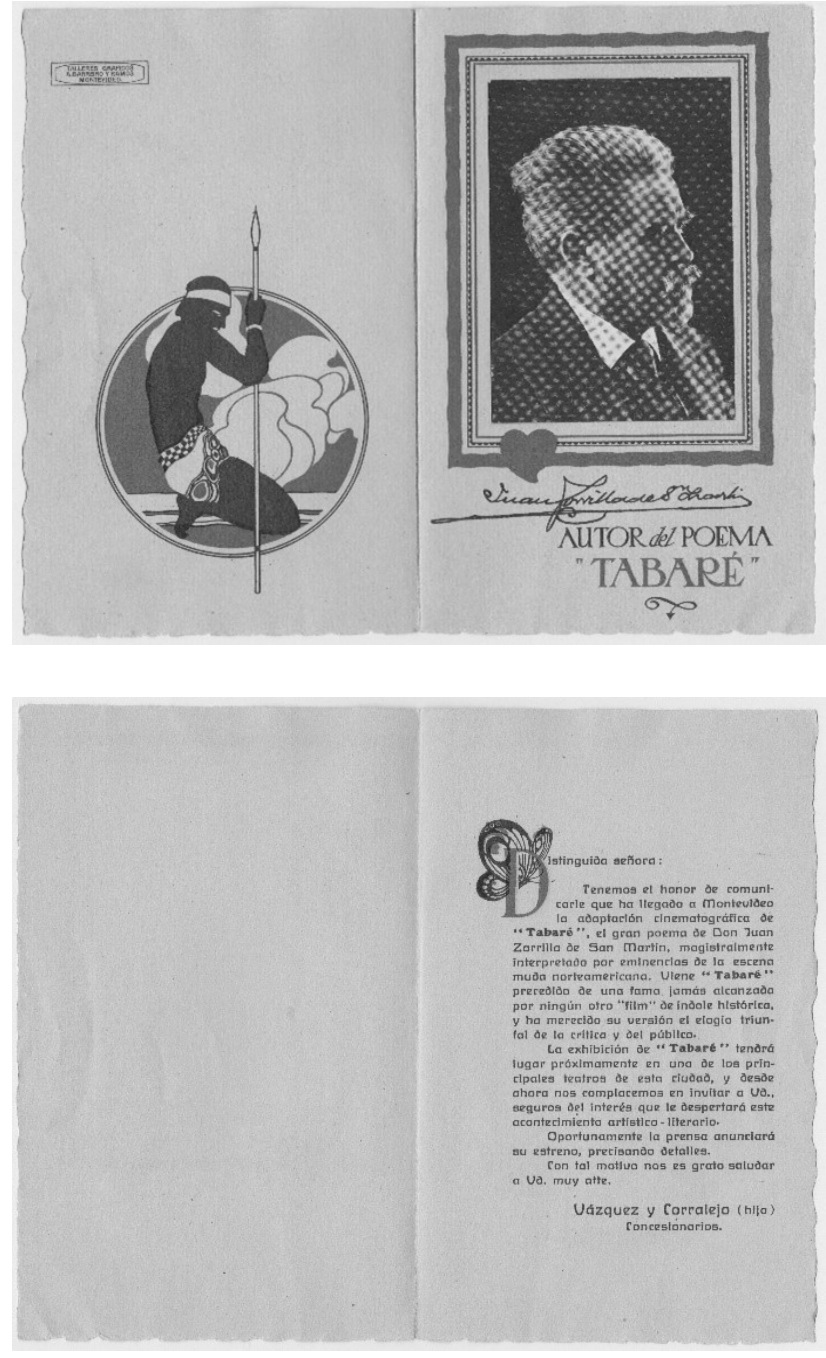

Figuras 8-9: Folleto promocional de Tabaré

$\mathrm{Su}$ tapa luce la fotografía del poeta de la patria, su firma y la inscripción "autor del poema Tabaré" y, en la contratapa, la imagen deco del indio de ojos azules. En su interior, se afirma, dirigiendo el discurso a una hipotética "distinguida señora" que este filme "magistralmente interpretado por eminencias de la escena muda norteamericana”, llegó a Montevideo.

El folleto no indica, como era de esperarse, la fecha ni lugar de estreno. A nivel comunicativo, el programa solo informa sobre el (falso) origen del filme e instituye su target. Para mayo de 1921, la película vuelve al Cine Rex, ahora distribuida por Max Glücksmann, con producción de "una importante casa americana y la dirección de nuestro compatriota el doctor Pedro Erasmo Callorda" ( $\mathrm{La}$ Mañana [Uruguay], 22 de mayo de 1921, p. 5). Fue una (¿última?) vuelta de tuerca en las apropiaciones del filme mexicano. Los lazos de afinidad que lo habían fundado y sostenido se habían roto.

\section{Romanticismo y paz nacional: Brenda}

Enmudecieron; disipáronse las sombras de las frentes; buscáronse las manos en cariñosa alianza, la mano blanca y pura de la virgen y la mano del matador...

La pareja pasó tranquila y risueña, leyéndose en sus rostros una promesa perdurable de paz y ventura.

\section{Eduardo Acevedo Díaz, Brenda}

Brenda, dirigida por Martínez de la Pera y Gunche y protagonizada por Enna Randal, Regé Leroy, Horacio Dyali y Nelo Cosimi, se estrena en Buenos Aires el 14 de octubre de 1921, tras una exhibición privada el 4 de octubre (Mafud, 2016, p. 363). ${ }^{9}$ Pero su gestión data de 1917: el guion es preparado en ese año por el periodista Joaquín E. Rimbau, de la revista Caras y Caretas, y el proyecto presentado a la Asociación del Divino Rostro que lo descarta por inmoral

9:: Su distribución posterior se produciría en dos periodos: entre 1921 y 1924 (en 1921 se vendió una copia a la compañia İtalo-Chilena) y entre 1928 y 1931 (Mafud, 2016, p. 365). 
(Mafud, 2016, p. 365). Lo retoma, en 1919, la productora Acevedo Díaz Film, formada posiblemente ad hoc.

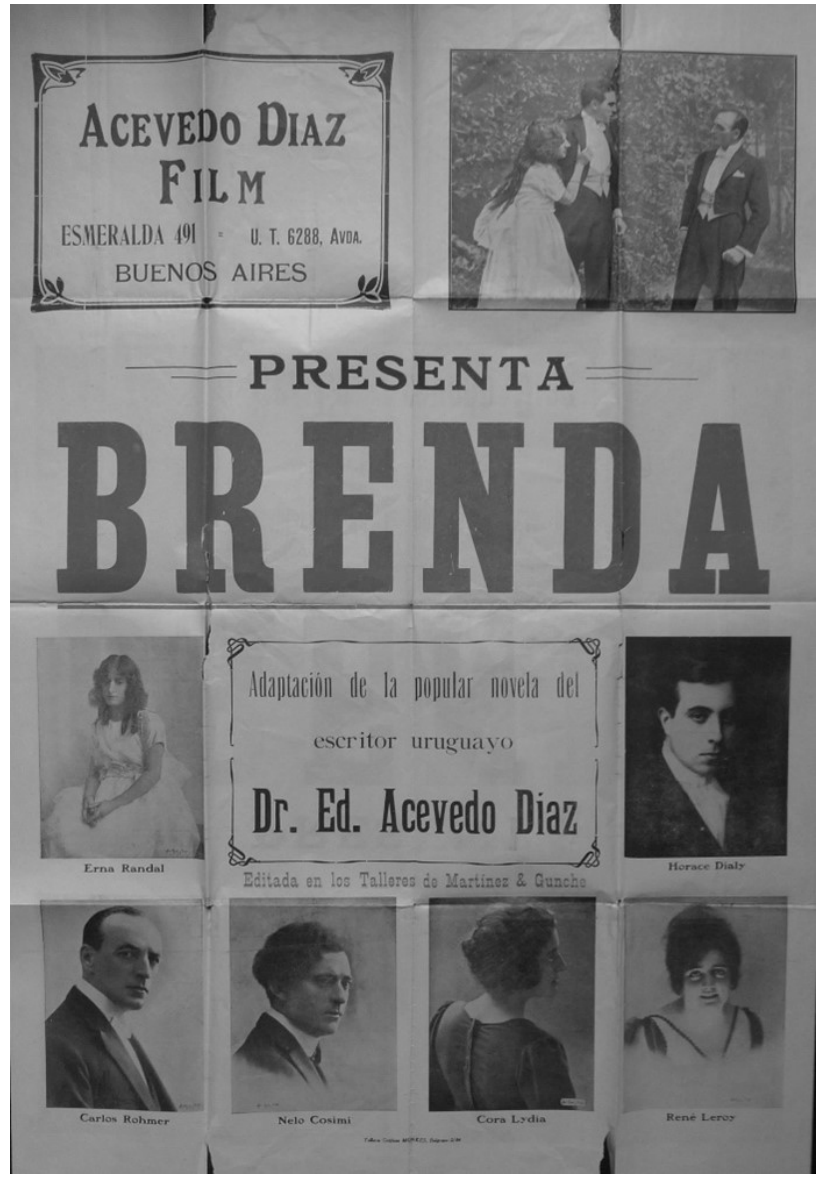

Figura 10: Afiche de Brenda, colección privada (Eduardo Orenstein)

Esta primera novela de Acevedo Díaz, ambientada en el último cuarto del siglo XIX, tiempos de relativa paz entre caudillos, narra la historia de amor entre Brenda y Raúl, marcada por las pasadas contiendas fratricidas (Raúl mató en combate al padre de la protagonista) y su resolución pacífica (el casamiento final entre los protagonistas), cierre simbólico y pedagógico para la necesaria paz nacional, impulso que guiaría la pluma del escritor durante toda su carrera.

En el taller de Martínez y Gunche se filma la mayoría de los interiores y parte de los exteriores en Montevideo, el cerro, playas y paseos (Mafud, 2016, p. 365). La empresa, de hecho, anuncia en marzo el viaje de los productores y "los principales intérpretes" hacia Uruguay para tomar las últimas escenas y completarla para abril (Excelsior [Argentina], 314, 17 de marzo de 1920, p. 1677). El dato no es menor porque anticipa al público local -como se había hecho a propósito de Tabaré- la atención por la autenticidad de los ambientes y, en definitiva, la "verosimilitud" geográfica que la empresa quería imprimirle a la película. Este gesto -la nota y el viaje- profundiza la "afınidad" transnacional que le dio inicio. Ya terminada, su promoción, memoriosa quizá de las críticas negativas que atacaron a la novela en su momento, destaca que la película "ganará en el concepto de muchos, por cuanto la acción resulta más rápida, sin menoscabo de la belleza literaria, intensificando la emoción que causan muchas de sus escenas" (Imparcial Film, IV, 129, 11 de octubre de 1921). Y no es menor este voto por la "agilidad": los tiempos en que la "fidelidad" era la única virtud de las adaptaciones parecían ir dejando paso a posiciones más articuladas como la de Joaquín de Vedia en relación con Los muertos.

Siguiendo las reglas de la época, una extensa nota previa relata de manera pormenorizada su trama "para aquellos que no la hayan leído" (Imparcial Film, IV, 129, 11 de octubre de 1921). En ella el complicado amor central entre Brenda y Raúl funciona en paralelo al triángulo fatal entre la humilde Cantarela, el rico Zelmar y el pescador Gerardo, que la novela sobrevolaba. Esta otra historia, como se señala desde la nota, permite no solo incrementar la intriga y dinamizar la acción, sino también hacer espacio a la representación de los más humildes, un plus de entretenimiento en el cine burgués local y global de la época. Y si resulta imposible comprobar, perdida la película, que el contrapunto se produjera efectivamente, la previa citada, además de darle lugar a la segunda historia "en palabras", ostenta una diagramación que apoya esta hipótesis. 




Figura 11: Las tramas en paralelo de Brenda (Imparcial Film, IV, 129, 11 de octubre de 1921)

Simétricas, las dos páginas que se le dedican contienen seis fotos de escena donde se equilibra perfectamente esa intriga en paralelo: tres a la izquierda protagonizadas por Brenda o su ambiente (lo que podría ser los externos del Teatro Solís, el parque, la clínica donde yace el cuerpo sin vida de Cantarela, enmarcado por el saber médico); tres a la derecha por Cantarela (la playa, la choza con su padre agonizante y, finalmente, con un Gerardo iracundo, sintesis perfecta del amor filial y pasional). La película de Martínez y Gunche hace, además, un ajuste temporal que la descripción no releva como tal: la fratricida Revolución de las Lanzas, liderada por Timoteo Aparicio en 1870, que había enmarcado a la novela, es reemplazada por la Revolución de 1904, llevada a cabo por Aparicio Saravia, otro caudillo del Partido Nacional.
A la exigencia de "velocidad" del nuevo medio se agrega la de actualidad: la contienda de 1904 era más cercana a la audiencia de 1921 e icónica por su carácter de última revolución caudillista. Brenda cerraba -definitivamente, se esperaba- una herida.

En Montevideo se anuncia su estreno en abril de 1923, como parte de un completo "Bijou programa" de la compañía argentina Cinematográfica Sud Americana integrado por largometrajes norteamericanos, españoles e italianos y mediometrajes cómicos (Reseña. Revista ilustrada, II, 11, abril 30 de 1923, p. 2). Para octubre del mismo año, en cambio, pasa a integrar el programa de la "compañía de reciente fundación” Selección Nacional, distribuidora del argentino Juan Dasso (el mismo que distribuiría Los muertos), junto con otras dos adaptaciones literarias 
argentinas producidas en los laboratorios de Martínez de la Pera y Gunche: Fausto, de Estanislao Del Campo (Rohmer, 1922) y La casa de los cuervos, de Hugo Wast (Rohmer, 1923) (Montevideo Film, 1, 1, 20 de octubre de 1923, p. 30). Y se reitera la promesa, al mes siguiente, reseñando el éxito de La casa de los cuervos, replicando el de Fausto pues "pocos serán los rioplatenses que desconozcan el interés de la obra que consagró al poeta argentino Estanislao del Campo", y adelantando, tras Brenda, el de El puñal del mazorquero, trasposición del relato La hija del mazorquero de Juana Manuela Gorriti (Torres Ríos, 1923) (Montevideo Film [Uruguay], 1, 2, 6 de noviembre de 1923). Pese a que, hasta ahora no se encontraron datos de su efectivo estreno en el país, es posible pensar su "eventual" presencia en el sistema cinematográfico nacional, a diferencia de las espontáneas relaciones transnacionales previamente tratadas, como parte de un proyecto de difusión de una literatura inclusivamente rioplatense.

\section{Conclusiones}

Los tres casos analizados permitieron indagar los términos en que se dieron concretamente las "afinidades" de ese "transnacionalismo" que enmarcó el trabajo, tal como fue definido por Hjort (2010). Estas afinidades supusieron la discusión de las adaptaciones en términos de adherencia no solo a lo textual, sino a la verosimilitud histórica y geográfica de la representación. Interesa, además, que una de las constantes en la recepción de las películas implicara la apropiación de esas obras ajenas como nacionales, regionales y, con base en ello, la (re) definición de lo extranjero, en su mayoría identificado con la industria norteamericana. La presencia tanto en el espacio de los teatros y cines como en el de los diarios capitalinos, también permitió identificar las posiciones y usos que se hizo de dichas películas. Precisamente, a través de la revisión de los usos internos y externos de las películas, el artículo buscó mostrar parte de las dinámicas discursivas y las prácticas puestas en juego. Señaló, en relación con Los muertos, de qué manera se instalaron en el campo ciertas tensiones, diferentes en cada orilla del Plata. En Argentina fue espacio de una tirantez que involucró el moralismo mainstream de los exhibidores y un discurso intelectual que espació de la defensa estética (y la especificidad del medio) a los argumentos cientificistas, éticos, pedagógicos. Para el Uruguay, en cambio, la película se volvió -aplanada toda rispidez "ideológica" sancheana- perfecto instrumento del discurso moralizador y de intervención social y sanitaria por parte de la Liga Uruguaya contra el Alcoholismo. Para el Tabaré mexicano el artículo reseñó su lugar en la filmografía mexicana como confluencia de discursos nacionalistas y latinoamericanistas, y de fricciones con un imperialismo que ganaba terreno en el continente, para agregar a la producción crítica sobre la película el complejo desembarco autóctono. El artículo expuso, en este sentido, las dinámicas de la distribución en Uruguay declinadas en dos etapas: una primera que difundió la película como producción mexicana y una segunda en que se cancelaba su mexicanidad para insistir, en cambio, en su (falsa) producción norteamericana, la temática uruguaya y la filiación católica. Finalmente se revisó, en relación con Brenda, su instalación en el sistema a través de sus "intervenciones" sobre la novela original.

Estos procesos dieron cuenta tanto de una reflexión sobre las especificidades del pasaje intermediático como de la reescritura como espacio privilegiado para apelar al público contemporáneo (especialmente a través de la actualización histórica). La investigación quiso agregar otra pieza al puzle de unas relaciones intercontinentales que, durante el periodo silente, se revelan cada vez más necesarias. Un puzle que está casi todo por armar y cuyo armado supuso aquí, como supone a menudo en el campo silente dada la pérdida de las cintas, el rescate de fuentes secundarias, también ellas a menudo extraviadas, arruinadas, parciales. 


\section{Referencias}

Baccino Ponce de León, N. (1981). Brenda en el mundo narrativo de Eduardo Acevedo Díaz. Revista de la Biblioteca Nacional, 21, 33-120.

Bauck, S. (2016). Nüchterne Staatsbürger für junge Nationen: Antialkoholaktivismus in einer atlantischen Welt (Buenos Aires und Montevideo, 1876-1933) (Tesis doctoral). ETH Zürich, Suiza. https://doi. org/10.3929/ethz-a-010735810

Bongers, W., Torrealba, M. J. y Vergara, X. (Eds.). (2011). Archivos i letrados. Escritos sobre cine en Chile 1908-1940. Santiago, Chile: Cuarto Propio.

Borge, J. (Ed.). (2005). Avances de Hollywood. Crítica cinematográfica en Latinoamérica, 1915-1945. Buenos Aires, Argentina: Beatriz Viterbo.

Bouret, D. (2009). El consumo de vinos en el Uruguay del Novecientos. El desarrollo de la industria Vitivinícola vrs. Campañas antialcoholistas. Boletín Americanista, LIX(59), 155-176. Recuperado de https://www.raco.cat/index.php/BoletinAmericanista/article/download/143860/195538

Braselli, G. (1998). Florencio Sánchez en la escena nacional: 1900-1910. En 0. Pellettiery y R. Mirza (Eds.), Florencio Sánchez entre las dos orillas. Buenos Aires, Argentina: Galerna.

Cuarterolo, A. (2017). Antes de Babel. Prácticas transnacionales en el cine mexicano y argentino del período silente. En A. L. Lusnich, A. Aisemberg y A. Cuarterolo (Eds.), Pantallas transnacionales. El cine argentino y mexicano del período clásico (pp. 1-18). Buenos Aires, Argentina: Imago Mundi/Cinemateca Nacional de México.

Cúneo, D. (1941). Teatro Completo de Florencio Sánchez. Buenos Aires, Argentina: Editorial Claridad.

Dávalos Orozco, F. (Ed. y Pról.). (1998). Argumento de Tabaré. México D- F-, México: Cineteca Nacional/Albedrío.

Dubatti, J. (2010). Florencio Sánchez y la introducción del drama moderno en el teatro rioplatense. Biblioteca Virtual Miguel de Cervantes. Recuperado de http://www.cervantesvirtual.com/nd/ark:/59851/bmcfj306

Hjort, M. (2010). On the plurality of cinematic transnationalism. En N. Durovicova y K. Newman (Eds.), World, Cinemas, Transnational Perspectives (pp. 12-33). New York, NY: Routledge.

Lusnich, A. L. (2016). Transferencia de saberes y de tecnología entre el cine argentino y mexicano del período clásico-industrial. En M. Villarroel (Coord.), Memorias y representaciones en el cine chileno y latinoamericano (pp. 103-121). Santiago de Chile, Chile: LOM.
Mafud, L. (2016). La imagen ausente. El cine mudo argentino en publicaciones gráficas. Catálogo. El cine de ficción (1914-1923). Buenos Aires, Argentina: Teseo.

Malosetti, L. (2018). Tabaré Cosmopolita: 130 años, 1888-2018: Migraciones y ambivalencias del héroe trágico. Montevideo, Uruguay: MEC.

Miquel, A. (2018). Recepción y contexto de dos adaptaciones mexicanas al poema Tabaré de Juan Zorrilla de San Martín. En A. Miquel, F. Delmar, L. Elizalde y A. Tornero (Eds.), Intermedialidades en las artes visuales y la literatura (pp. 45-82). México D. F., México: Juan Pablos Editor/Universidad Autónoma del Estado de Morelos.

Real de Azúa, C. (1950). Ambiente espiritual del 900. Número, 2(6-7-8), 15-36.

Rela, W. (1967). Prólogo. En Florencio Sánchez Teatro. Colección de Clásicos Uruguayos. Montevideo, Uruguay: Biblioteca Artigas.

Sánchez García, J. M. (2013). Historia del cine mexicano (1896-1929), edición facsimilar, compilación, introducción e índices de Federico Dávalos Orozco y Carlos Arturo Flores Villela. México D. F., México: Filmoteca de la UNAM.

Torello, G. (2013). Por ese terrible pulpo que todo lo quiere abarcar y dominar. Debate entre revistas especializadas a propósito de Max Glücksmann. Actas del II Simposio lberoamericano de estudios comparados sobre cine y audiovisual: perspectivas interdisciplinarias. Debates del cine y la historia. Buenos Aires, Argentina. Editorial de la Facultad de Filosofía y Letras/UBA

Torello, G. (2018). La conquista del espacio. Cine silente uruguayo (19151932). Montevideo, Uruguay: Yaugurú.

Vidal, D. (2010). Florencio Sánchez y el anarquismo. Montevideo, Uruguay: Banda Oriental/Biblioteca Nacional/Facultad de Humanidades y Ciencias de la Educación/UdelaR.

Williams, R. (1980). Marxismo y literatura. Barcelona, España: Península. Wolf, S. (2001). Cine/Literatura. Ritos de pasaje. Buenos Aires, Argentina/ Barcelona, España/México D. F., México: Paidós.

\section{Contribución autoral}

a) Concepción y diseño del trabajo; b) Adquisición de datos; c) Análisis e interpretación de datos; d) Redacción del manuscrito; e) revisión crítica del manuscrito.

G. T. ha contribuido en $a, b, c, d$, e.

Editor responsable: L. D. 